Isadora Martins Montiel ${ }^{1}$

Alessandra Troian ${ }^{2}$

Raquel Breitenbach ${ }^{3}$

\title{
CONDICIONALIDADES E EFETIVIDADE DO PROGRAMA BOLSA FAMÍLIA: UMA ANÁLISE DE 2000 A 2014
}

\author{
CONDITIONALITIES AND EFFECTIVENESS OF THE FAMILY \\ ALLOWANCE PROGRAM: ANALYSIS OF 2000 TO 2014
}

\begin{abstract}
Resumo
Nas últimas décadas o debate acerca da pobreza vem ganhando destaque no cenário global. No Brasil, a pobreza sempre foi um fator de relevância, já que ela atinge parte significativa da população. O presente estudo objetiva analisar a efetividade do Programa Bolsa Família (PBF) através do acompanhamento dos dados das condicionalidades nas áreas da educação e da saúde no período de 2005 a 2014. Metodologicamente a pesquisa classifica-se como qualitativa, a partir do método dedutivo. Realizou-se a análise de dados secundários do Departamento de Informática do Sistema Único de Saúde (DATASUS); do Ministério do Desenvolvimento Social e Agrário (MDS); e de relatórios do Programa das Nações Unidas para o desenvolvimento - Brasil (PNUD-BR). Os resultados indicam que o Programa Bolsa Família melhorou as condições de vida de seus beneficiários através do auxílio financeiro e, principalmente, pelo acesso à educação e a saúde, aumentando os níveis de frequência escolar e acompanhamentos médicos básicos. A melhora nas condições de vida também fica evidente nos resultados do Índice de Desenvolvimento Humano do período.
\end{abstract}

Palavras-chave: Transferência de renda. Condicionalidades. Miséria. Desenvolvimento. Programa Bolsa Família.

\section{Abstract}

In the last decades the debate about poverty has been gaining prominence in the global scenario. In Brazil, poverty has always been a factor of relevance, since it affects part of the population. The present study aims to analyze the effectiveness of the Bolsa Família

Bacharel em Ciências Econômicas, Universidade Federal do Pampa, Sant'Ana do Livramento.

E-mail: isadora.montiel@hotmail.com.

2 Doutora em Desenvolvimento Rural, professora adjunta na Universidade Federal do Pampa, Campus Santana do Livramento.E-mail: alessandratroian@unipampa.edu.br.

Doutora em Extensão Rural, professora adjunta no Instituto Federal do Rio Grande do Sul, Campus Sertão.E-mail:raquel.breitenbach@sertao.ifrs.edu.br 
Program (PBF) through the monitoring of conditionalities data in the areas of education and health in the period from 2005 to 2014 . Methodologically the research is classified as qualitative, using the deductive method. The analysis of secondary data of the Department of Informatics of the Unified Health System (DATASUS) was carried out; of the Ministry of Social and Agrarian Development (MDS); and reports of the United Nations Development Program - Brazil (UNDP-BRAZIL). The results indicate that the Bolsa Família Program has improved the living conditions of its beneficiaries through financial assistance and, mainly, access to education and health, increasing levels of school attendance and basic medical accompaniments. The improvement in living conditions is also evident in the results of the Human Development Index of the period.

Keywords: Income transfer. Conditionalities. Misery. Development. Family Allowance Program.

\section{INTRODUÇÃO}

O debate acerca dos problemas de distribuição de renda e pobreza iniciou em meados dos anos 1970, quando se constatou que, apesar da economia apresentar crescimento econômico, o aumento da produção não era absorvido pela sociedade em geral, tanto em países desenvolvidos como para países em desenvolvimento. (ROCHA, 2003) No entanto, para se conceber políticas públicas voltadas para a redução da pobreza, é necessário compreender que este é um fenômeno complexo, com inúmeras abordagens, podendo ser analisada exclusivamente pelo viés da renda ou considerando aspectos sociais. (CRESPO; GUROVITZ, 2002)

No sentido do combate à pobreza e a desigualdade social, no final da década de 1980 o Brasil realizou algumas conquistas. Destaca-se a Constituição Federal de 1988 que assegurou que o Estado deveria garantir educação e saúde aos seus cidadãos; bem como o fim do regime militar que perdurou durante duas décadas e o retorno das eleições diretas, garantindo ao povo o poder de escolher a autoridade máxima no país. (MARANGONI, 2012; SOARES; SÁTYRO, 2009)

Apesar destas conquistas, a pobreza e a desigualdade social se acentuaram na década seguinte. Parte disto pode ser explicado pela estratégia de adotar políticas neoliberais no Brasil. A partir do Consenso de Washington foi orientado que a América Latina realizasse o processo de abertura comercial e financeira, através das privatizações de estatais e desregulamentação do mercado financeiro, como também reformas trabalhistas e previdenciárias. (CASTRO, 2005; SOUZA, 2008)

Para combater a pobreza e a desigualdade social, o Brasil começou a investir em políticas de transferência de renda condicionada. As transferências de renda são programas onde o governo auxilia os indivíduos com benefícios financeiros, em troca do cumprimento de determinadas contrapartidas. Na dé- 
cada de 1990, apenas um programa com essas características foi implementado em âmbito federal, o Programa da Erradicação do Trabalho Infantil, que tinha como objetivo tirar do trabalho mais de um milhão de crianças e adolescentes. (GIAMBIAGI, 2005; SILVA, 2005) No entanto, na década de 2000 as políticas de transferência de renda condicionada começaram a destacar-se no país. No segundo mandato de Fernando Henrique Cardoso foram implementados programas de transferência de renda voltados para a educação e saúde, o Bolsa-Escola e Bolsa Alimentação, respectivamente. Em 2003 foi implementado o Programa Fome Zero, objetivando oferecer segurança alimentar aos brasileiros. Um dos seus principais instrumentos é o Programa Bolsa Família (PBF), o qual busca atender as famílias brasileiras que se encontram em situação de pobreza e extrema pobreza.

A partir do histórico de pobreza e desigualdade de renda enfrentada pelo Brasil e tendo em vista a inserção do $\mathrm{PBF}$, o presente artigo tem como objetivo analisar a efetividade do programa a partir do cumprimento das condicionalidades do PBF nas áreas da educação e da saúde no período de 2005 a 2014. Para tanto, a metodologia classifica-se como qualitativa, a partir da análise de dados do Departamento de Informática do Sistema Único de Saúde (DATASUS); do Ministério do Desenvolvimento Social (MDS); e de dados secundários de relatórios do Programa das Nações Unidas para o desenvolvimento - Brasil (PNUD-BRASIL).

\section{A POBREZA E OS PROGRAMAS DE TRANSFERÊNCIA DE RENDA}

Entre as diversas formas de abordagem da pobreza, destacam-se a pobreza absoluta e a pobreza relativa. A pobreza absoluta está ligada ao fator de sobrevivência física, caracterizada pela falta daquilo que um indivíduo necessita para ter uma vida saudável. (ROCHA, 2003) Já a pobreza relativa relaciona-se com a desigualdade na distribuição de renda, são as pessoas que estiverem em uma classe social mais baixa do que aquela que predomina na esfera social da qual fazem parte. (CRESPO; GUROVITZ, 2002; ROCHA, 2003)

Outra abordagem em relação à pobreza é a da insuficiência de renda. Tal perspectiva considera pobre o indivíduo que não possui os recursos mínimos necessários para conseguir sobreviver. Para tanto, deve-se determinar um valor monetário que consiga atender em média as necessidades desses indivíduos e serão considerados pobres todos aqueles que possuírem renda menor ao valor pré-estabelecido. (LEÃO, 2004; ROCHA, 2003) O Banco Mundial criou em 1985 um parâmetro de pobreza que considera como pobres todos os que recebem de US\$ 1 a US $\$ 2$ dólares por dia relacionando com a paridade do 
poder de compra, também em dólares. (INSTITUTO DE PESQUISA ECONÔMICA APLICADA, 2010; NERI; MELO; MONTE, 2012)

Em contraponto a teoria da insuficiência de renda, há a abordagem "Seniana" da privação de capacidades. Esta vai à contramão das visões tradicionais, destacando que há outras variáveis que influenciam nesse fenômeno. Nesse caso, uma análise pela perspectiva só da renda será incompleta e inadequada. (SEN, 2000) Os pressupostos desta abordagem baseiam-se na importância de fatores intrínsecos. Por exemplo, um indivíduo pode não ter acesso a saneamento básico ou ter uma baixa expectativa de vida, apesar de ter uma renda acima da linha da pobreza. Portanto, a renda não é o único fator que influencia na expansão das capacidades. Por outro lado, pode haver local onde os indivíduos têm baixa renda, mas as condições de vida são melhores do que outro em que as pessoas têm a mesma renda, mas enfrentam outras privações. (SEN, 2000)

Nesse contexto de discussão e conceituação sobre pobreza, têm destaque as consequentes ações de políticas públicas de transferência de renda na redução da pobreza. Tais políticas buscam a transferência de recursos financeiros por parte do governo com destino as famílias consideradas pobres e em estado de carência. (JESUS; SILVA; BOAVENTURA, 2012; SILVA, 2005) Já os programas de transferência de renda condicionada procuram garantir a inclusão dos mais pobres na sociedade por meio de suas condicionalidades. (CUNHA, 2012)

As condicionalidades desse tipo de programa buscam assegurar que as ações do governo, na tentativa de reduzir a pobreza, tenham resultados positivos no desenvolvimento, além de somente o repasse da renda pelo governo. Uma das condicionalidades geralmente encontradas nesse tipo de programa está relacionada à educação. Ou seja, as famílias beneficiárias devem garantir que as crianças tenham determinada frequência escolar. Combinando renda e educação os programas buscam, no longo prazo, quebrar o ciclo de pobreza que passa de pai para filho. (MONTEIRO; FERREIRA; TEIXEIRA, 2009)

Durante a década de 1990 o Brasil sofria com a instabilidade da economia, graças às crises econômicas e financeiras que já advinham da década passada e, também, da implementação das medidas estabelecidas pelo Consenso de Washington, gerando efeitos negativos à população, especialmente nas camadas mais pobres. Como alternativa de superação dessa situação, o governo brasileiro passou a criar os primeiros programas de transferência de renda condicionada (SOUZA, 2008), os quais são demonstrados no Quadro 1.

O PBF foi criado em 2003 e unificou os programas de transferência de renda que já haviam sido implantados pelo governo Fernando Henrique Cardoso (FHC): Bolsa Escola, Auxílio Gás, Bolsa Alimentação e Cartão Alimenta- 
ção. (TAVARES et al., 2009) É um programa de transferência de renda condicionada que busca beneficiar as famílias que estão em vulnerabilidade econômica. No período de sua criação, eram beneficiários do programa as famílias que tivessem renda familiar per capita inferior ou igual a R \$ 50/mês. Já em 2014, depois de um reajuste do governo, o valor passou a ser concedido a famílias com renda per capita de até $R \$ 77 /$ mês. Os beneficiários recebem um valor fixo, visto que estão na faixa de pobreza extrema estabelecida pelo programa. (FERRER, 2015; SOUZA; OSORIO; SOARES, 2011)

Quadro 1 - Programas de transferência de renda condicionada no Brasil

\begin{tabular}{|l|l|l|}
\hline Programas & $\begin{array}{l}\text { Ano de criação/ } \\
\text { governo }\end{array}$ & Objetivo \\
\hline $\begin{array}{l}\text { Erradicação } \\
\text { do Trabalho } \\
\text { Infantil }\end{array}$ & $\begin{array}{l}\text { 1996 - Fernando } \\
\text { Henrique Cardo- } \\
\text { so (FHC) }\end{array}$ & $\begin{array}{l}\text { Retirar mais de um milhão de crianças e adoles- } \\
\text { centes do trabalho infantil, através da doação de } \\
\text { bolsas de estudos. (GIAMBIAGI, 2005; SOARES; } \\
\text { SÁTYRO, 2009) }\end{array}$ \\
\hline Bolsa-Escola & 1990 - FHC & $\begin{array}{l}\text { Diminuir a pobreza no curto prazo; com aumento } \\
\text { da escolaridade; reduzir a pobreza ao longo do } \\
\text { tempo; reduzir o trabalho infantil e atuar como uma } \\
\text { rede de proteção aos beneficiários. } \\
\text { (FERRO; KASSOUF, 2005; VALENTE, 2003) }\end{array}$ \\
\hline $\begin{array}{l}\text { Bolsa } \\
\text { Alimentação }\end{array}$ & 2001 - FHC & $\begin{array}{l}\text { Gerido pelo Ministério da Saúde buscava propor- } \\
\text { cionar e melhorar o acesso à saúde e nutrição as } \\
\text { famílias vulneráveis socioeconomicamente com } \\
\text { crianças de até seis anos, mulheres grávidas e } \\
\text { amamentando. (BATISTA, 2007) }\end{array}$ \\
\hline Auxílio Gás & 2001 - FHC & $\begin{array}{l}\text { Gerido pelo Ministério de Minas e Energia, transfe- } \\
\text { ria bimestralmente R\$ 15 para compra de um bo- } \\
\text { tijão de gás. Sem condicionalidade. Beneficiários: } \\
\text { famílias inscritas no Cadastro Único, com renda } \\
\text { per capita de meio salário mínimo por mês. } \\
\text { (ROCHA, 2013) }\end{array}$ \\
\hline Fome Zero & $\begin{array}{l}\text { 2003 - Luís Inácio } \\
\text { Lula da Silva }\end{array}$ & $\begin{array}{l}\text { Atua na esfera Federal, Estadual e Municipal. Po- } \\
\text { lítica social de combate à fome no curto prazo, um } \\
\text { grupo de políticas públicas de combate à fome e } \\
\text { desnutrição no país, como o Programa Bolsa Fa- } \\
\text { mília. (SOUZA; RAMALHO; FORTALEZA, 2003) }\end{array}$ \\
\hline
\end{tabular}

Fonte: elaborado pelas autoras.

O benefício variável é outro tipo de auxílio concedido pelo PBF. A princípio, esse benefício era concedido a famílias que tivessem acima da linha de pobreza extrema e renda per capita de até $\mathrm{R} \$ 100 / \mathrm{mês}$, com crianças e adolescentes de $\mathrm{O}$ a 14 anos, podendo ser beneficiadas até três crianças e adolescentes por família. Com reajustes no ano de 2014, poderiam receber esse benefício às famílias com renda mensal individual de até R\$154,00. (FERRER, 2015; SOARES, SÁTYRO, 2009) 
Em 2003, no primeiro ano de atuação PBF, o valor do benefício fixo era de $\mathrm{R} \$ 50$ para as famílias consideradas de extrema pobreza pelo programa. Já os benefícios variáveis eram no valor de $\mathrm{R} \$ 15$, podendo chegar até $\mathrm{R} \$ 45$ por família. Para receber o benefício variável, as famílias deveriam ter na sua composição familiar crianças de o a 14 anos, gestantes e nutrizes. (BATISTA, 2007)

Em 2014, o valor do benefício fixo era de R $\$ 77$ para as famílias na faixa de extrema pobreza. Já o benefício variável para crianças e adolescentes de o a 15 anos, para as gestantes e para nutrizes era $\mathrm{R} \$ 35$, sendo possível beneficiar até cinco indivíduos por família. Havia também o benefício variável para famílias com adolescentes de 16 a 17 anos, que podia beneficiar até dois indivíduos por família e tinha valor de $\mathrm{R} \$ 42$. No ano de 2013 foi criado o benefício para superação da extrema pobreza que auxiliava as famílias que, mesmo após receberem os outros tipos de benefícios do PBF, continuassem com renda per capita inferior a $\mathrm{R} \$$ 77. (FERRER, 2015)

Como o PBF é um programa de transferência de renda condicionada, é necessário que as famílias cumpram com compromissos, inclusive todas as crianças e adolescentes com idade entre $\mathrm{o}$ a 15 anos que não recebem o benefício variável. As condicionalidades são:

- Saúde: 1 - Manter a vacinação em dia e realizar o acompanhamento nutricional das crianças de 0 a 7 anos; 2 -Gestantes realizarem o Pré-natal; 3 - As gestantes e nutrizes devem participar das atividades educativas desenvolvidas pelas equipes de saúde sobre aleitamento materno e alimentação saudável (BRASIL, 2016a);

- Educação: 1 - Matrícula e frequência escolar acima de $85 \%$ para crianças e adolescentes de $\mathrm{O}$ a 15 anos. (BRASIL, 2016a)

O objetivo principal das condicionalidades é proporcionar a formação de capital humano no longo prazo, para ser possível a redução da pobreza. (BATISTA, 2007; SOUZA; OSORIO; SOARES, 2011) As consequências do descumprimento das mesmas estão divididas em quatro fases: $1^{a}$ ) Advertência à família beneficiária, mas sem lhe suspender o benefício; $2^{a}$ ) Bloqueio do benefício por um mês, recebendo-o no próximo mês juntamente com a nova parcela do auxílio; $3^{\text {a }}$ ) Suspensão pelo período de dois meses, sem poder cobrar o auxílio bloqueado no próximo pagamento; $4^{\mathrm{a}}$ ) Cancelamento, em que a família é excluída do programa Bolsa Família. (BRASIL, 2016b)

A partir do resgate das políticas públicas de transferência de renda desenvolvidas no Brasil e da descrição do PBF, a seguir apresentam-se os resultados obtidos na pesquisa realizada. 


\section{O PROGRAMA BOLSA FAMÍLIA: DO CUMPRIMENTO DAS CONDICIONALIDADES AO PROCESSO DE DESENVOLVIMENTO}

O presente estudo fez uma análise focada nas condicionalidades do PBF, que estão ligadas as condições de saúde e educação dos beneficiários. Acerca da saúde, as informações agregadas são divididas em seis categorias, conforme Quadro 2.

Quadro 2-Categorização das famílias beneficiadas pelo PBF

\begin{tabular}{|l|l|}
\hline $\begin{array}{l}\text { Categoria das } \\
\text { famílias do PBF }\end{array}$ & Descrição \\
\hline $\begin{array}{l}\text { a) Com perfil de } \\
\text { saúde }\end{array}$ & $\begin{array}{l}\text { Famílias beneficiárias do PBF que possuem entre os seus mem- } \\
\text { bros crianças menores de 7 anos e/ou mulheres em idade fértil } \\
\text { (10 a } 49 \text { anos) entre as quais devem } \\
\text { ser identificadas as gestantes. }\end{array}$ \\
\hline $\begin{array}{l}\text { b) Totalmente } \\
\text { acompanhadas }\end{array}$ & $\begin{array}{l}\text { Famílias inseridas no Bolsa Família são acompanhadas to- } \\
\text { talmente pela Secretaria Municipal de Saúde, com avaliação } \\
\text { antropométrica, monitoramento da carteira de vacinação das } \\
\text { crianças, realização do pré-natal } \\
\text { pelas gestantes beneficiárias. }\end{array}$ \\
\hline $\begin{array}{l}\text { c) Parcialmente } \\
\text { acompanhadas }\end{array}$ & $\begin{array}{l}\text { Casos em que o agente de saúde não consegue fazer o acom- } \\
\text { panhamento de toda a família, mas somente } \\
\text { de alguns integrantes dela. }\end{array}$ \\
\hline d) Não visitadas & $\begin{array}{l}\text { Consiste naquelas famílias que não comparecem nas Unidades } \\
\text { de Saúde para fazerem o acompanhamento e que não recebem } \\
\text { a visita de servidores da saúde em suas casas para convocarem } \\
\text { as mesmas a comparecerem } \\
\text { a Unidade de Saúde do município. }\end{array}$ \\
\hline $\begin{array}{l}\text { Famílias não localizadas pela Secretaria Municipal de Saúde } \\
\text { quando vai fazer a visita, tendo como base }\end{array}$ \\
\hline $\begin{array}{l}\text { f) Localizadas e } \\
\text { não acompanha- } \\
\text { das }\end{array}$ & $\begin{array}{l}\text { Famílias que o agente fez a visita no endereço certo, } \\
\text { mas não havia pessoas em casa. }\end{array}$ \\
\hline
\end{tabular}

Fonte: adaptado de DATASUS (2016).

Nesta seção são analisadas essas categorias considerando o período de 2005 a 2014, conforme é possível visualizar no Gráfico 1. Constata-se que das famílias com perfil saúde do PBF ocorreu crescimento constante no número de famílias nos anos iniciais, estabilizando-se a partir de 2007, voltando a crescer a partir de 2012, chegando a cerca de 12 milhões de famílias com perfil saúde, o que prosseguiu até o fim do período analisado. A quantidade de famílias totalmente acompanhadas cresceu, com pequenas oscilações ao longo do período. A principal oscilação com redução de famílias concentra-se na segunda vigência de 2008, estabilizando-se a partir de 2012. (DATASUS, 2016) 
Tratando-se das melhorias na área da saúde, as famílias beneficiárias do PBF mantém o cartão de vacinação em dia e as gestantes realizam o pré-natal adequadamente, bem como as famílias apresentam melhoria na alimentação e acessam medicamentos, resultado do incremento da renda. (SILVA; DALT, 2009) A combinação do benefício financeiro com o acesso a saúde proporciona melhores condições de vida a essa população, embora ainda tem muito a ser feito em relação à saúde, especialmente aumentando a capacidade das Unidades de Saúde dos municípios para que possam suprir a demanda dos referidos beneficiários. (CARVALHO, ALMEIDA, JAIME, 2014)

Em 2007, na $1^{a}$ vigência do ano, o número de famílias parcialmente acompanhadas continuou aumentando, alcançado o número mais alto em todo o período da análise, o que começou a diminuir a partir da $2^{a}$ vigência do mesmo ano. Posteriormente, em 2008 , houve queda no número de famílias parcialmente acompanhadas, voltando para um nível de cerca de 100 mil famílias na $2^{a}$ vigência. A partir de 2010 até a $1^{a}$ vigência de 2012 , mantiveram-se números estáveis, acima de 50 mil, mudando somente na $2^{\text {a }}$ vigência de 2012 , em que o número de famílias parcialmente atendidas baixou para cerca de $40 \mathrm{mil}$. A partir daí, os números se estabilizaram em torno de pouco mais de 50 mil famílias, mantendo-se assim até o fim do período analisado. No início do PBF havia maior acompanhamento parcial das famílias com perfil saúde, visto que o número de famílias beneficiárias era menor. (DATASUS, 2016) Com o decorrer dos anos do programa, o número de famílias parcialmente acompanhadas caiu circunstancialmente. 
Gráfico 1 - Análise comparativa de famílias com perfil saúde inseridas no PBF no período de 2005 a 2014, incluindo famílias totalmente acompanhadas, famílias parcialmente acompanhadas e famílias não visitadas

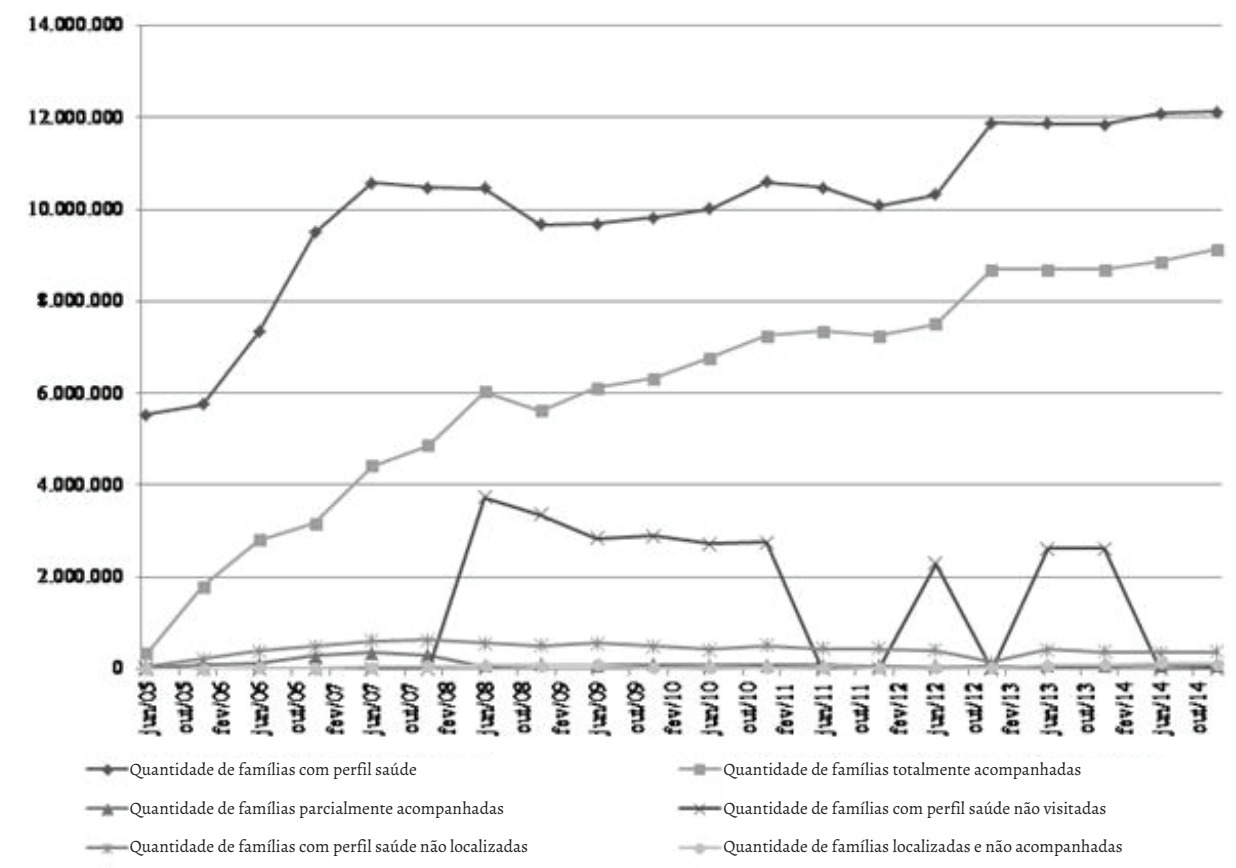

Fonte: adaptado de DATASUS (2016).

A análise também se concentrou na quantidade de famílias com perfil saúde não visitadas. Em comparação com o número de famílias com perfil saúde, até o ano de 2007, havia um alto nível de famílias não visitadas. A partir de 2008 esse número começou a cair ano a ano, estabilizando em torno de 2,5 milhões de famílias até o final do período analisado. Isto pode ser justificado pela falta de profissionais que pudessem exercer a função de comunicação a essas famílias, bem como o despreparo dos servidores que já trabalhavam no acompanhamento das condicionalidades. (CARVALHO; ALMEIDA; JAIME, 2014)

Acerca das famílias com perfil saúde não localizadas, considerando a Figura 1, nos primeiros anos o número de famílias dessa categoria vai crescendo, chegando em 2007 no pico. A partir de 2008 o número de famílias começa a reduzir, atingindo na $1^{\mathrm{a}}$ vigência de 2010 pouco mais de 400 mil famílias. De 2011 até a $1^{\text {a }}$ vigência de 2012 ocorreu estabilidade nos números de famílias não localizadas, ficando em torno de 400 mil famílias. Já na $2^{a}$ vigência de 2012 houve redução do número de famílias não localizadas.

A quantidade de famílias localizadas e não acompanhadas do PBF, apresentaram números muito próximos a zero no primeiro ano analisado, com cres- 
cimento constante ao longo do período e picos maiores na $1^{\text {a }}$ vigência de 2009 e a partir de 2013 até o fim do período. Destarte, houve aumento das famílias acompanhadas em relação aos anos iniciais do programa. Isso se refere à baixa infraestrutura e a falta de servidores para executarem o acompanhamento das famílias nos primeiros anos de implementação do PBF. (BATISTA, 2007) Por outro lado, a evolução do Programa com o tempo, aumentou o acesso das famílias às Unidades de Saúde dos municípios, pela preocupação em manter o recebimento do benefício e, consequentemente, fazendo com que essas famílias tivessem uma maior preocupação com a saúde.

Destaca-se que as condicionalidades relacionadas a saúde dizem respeito ao acompanhamento do calendário vacinal e do crescimento e desenvolvimento das crianças menores de sete anos de idade, realização de pré-natal e puerpério para gestantes e participação em atividades educativas sobre aleitamento e alimentação saudável. (SENA; BRANDÃO; DALT, 2016) Nesse sentido, o cumprimento das condicionadas relacionadas a saúde mostram-se satisfatórias e demonstram um amplo envolvimento dos gestores, equipes e profissionais de saúde da atenção básica. Ademais, cumprir tais condicionalidades implica reconhecer a importância da agenda, o compromisso e oportunidade no exercício da equidade, na garantia do acesso aos serviços básicos de saúde e, consequentemente, na redução das vulnerabilidades. (CAMPELO; NERI, 2013)

Tratando-se das condicionalidades da educação, o acompanhamento é feito pelo Ministério da Educação (MEC), por intermédio do sistema presença, que busca aperfeiçoar o acompanhamento desta condicionalidade, para tentar erradicar a evasão escolar. Com as informações repassadas pelo Ministério da Educação do quantitativo de beneficiários por cidades, os municípios podem realizar o acompanhamento das matrículas e frequência escolar e registrar os dados no sistema presença. $\mathrm{O}$ acompanhamento desta condicionalidade é realizado em cinco vigências anuais, por bimestres, excluindo os meses de janeiro e dezembro, pois são períodos de férias escolares. (BATISTA, 2007; BRASIL, 2016b)

Os dados das condicionalidades da educação, disponibilizados pelo Ministério do Desenvolvimento Social e Agrário, estão disponíveis a partir do ano de 2009. O acompanhamento das famílias beneficiárias no ano de 2009, como é observado na Figura 2, mostra que o cumprimento da frequência escolar por parte das famílias beneficiárias é quase total. 
Gráfico 2-Comparativo da frequência escolar das crianças e adolescentes de 6 a 15 anos das famílias pertencentes ao PBF, no período de 2009 à 2014, contemplando

frequência escolar, frequência escolar igual e superior a $85 \%$ e frequência escolar inferior a $85 \%$ - em termos absolutos

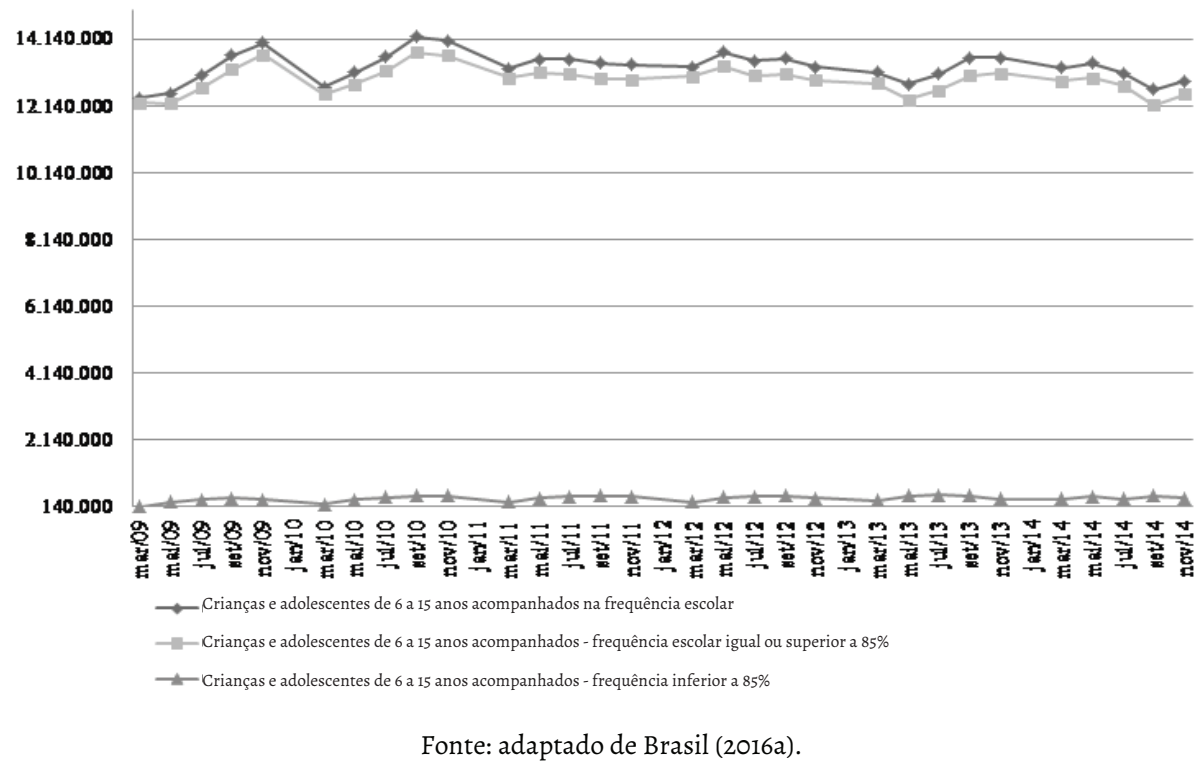

Houve oscilações no número de crianças que não atingiram a frequência escolar estipulada pelo PBF ao longo do período analisado. Tal oscilação, porém, deixa evidente que em todo período analisado o máximo de beneficiados que não atingiram a frequência escolar foi de 3,6\%. Ou seja, em todo período analisado mais de $96 \%$ das famílias cumprem com a condicionalidade. No entanto, a faixa etária requerida pela condicionalidade educacional do PBF tem sido criticada porque as matrículas no ensino fundamental são elevadas, atingindo cerca de $94 \%$ das crianças na faixa etária correspondente e $92 \%$ das crianças no quintil mais pobre. (SCHWARTZMAN, 2005; SOUZA, 2006)

Os efeitos das condicionalidades extrapolam a questão educacional, uma vez que o tempo que as crianças e adolescentes passam na escola é importante para além de garantir a transferência da renda do $\mathrm{PBF}$, já que os alunos também recebem alimentação no ambiente escolar. (ALBUQUERQUE NETO et al., 2015)

$\mathrm{O}$ PBF alcançou êxito no período analisado ao manter as crianças na escola, auxiliando a redução das desigualdades educacionais entre a população brasileira. (CRAVEIRO; XIMENES, 2013) Portanto, a condicionalidade da educação supostamente tem contribuído para redução da pobreza no longo prazo, já que tem proporcionado que crianças e adolescentes que antes não estudavam ou não permaneciam na escola - por diversas razões, por exemplo, falta de 
incentivo da família, necessidade de trabalhar em horário escolar, entre outros estejam condicionados a estudar para receber os recursos do programa.

Além de buscar a quebra do ciclo de pobreza que passa de pai para filho, as condicionalidades da educação também propiciam redução do trabalho infantil, visto que as crianças e adolescentes deixam de trabalhar para frequentarem a escola e continuarem recebendo o auxílio monetário do programa. (FAHEL; FRANÇA; MORAES, 2011) Além de proporcionar o aumento da escolaridade dos beneficiários do programa, também garantem a inclusão social destas famílias. Porém, para quebrar o ciclo geracional de pobreza, é preciso considerar, além da frequência escolar dos beneficiários, a qualidade do ensino ofertado pelo Estado. Se tal fator não tiver atenção, as condicionalidades da educação não terão os efeitos desejados. (PIRES, 2013)

As condicionalidades em educação do PBF devem ser pensadas numa perspectiva ampliada. Não deve se restringir aos seus efeitos práticos em termos de frequência escolar ou ganhos de escolaridade, mas, também, aos seus efeitos simbólicos, notadamente, o fortalecimento dos sentimentos de pertencimento e reconhecimento sociais por parte das entrevistadas gerados pelo cumprimento das condicionalidades em educação. (PIRES, 2013)

O acesso à educação e a saúde são fundamentais para a formação das capacidades humanas e a possibilidade de acesso às oportunidades. Assim, o Índice de Desenvolvimento Humano (IDH) torna-se uma forma eficaz para identificar o grau de bem-estar de uma população. O IDH combina indicadores econômicos e sociais, apoiando-se na perspectiva que o crescimento econômico deve melhorar a saúde e a educação das pessoas, bem como seus salários. (SAMUELSON; NORDHAUS, 2004) Neste trabalho, para analisar o impacto do PBF no país, utilizou-se o indicador econômico - IDH - do Brasil no período de 2005 a 2014.

O indicador busca medir o desenvolvimento humano dos países, considerando aspectos como a saúde e educação no seu cálculo. Visando verificar as melhorias nas condições de vida da população brasileira, a Figura 3 apresenta os resultados do IDH do Brasil no período de 2005 a 2014. 
Gráfico 3 - Índice de Desenvolvimento Humano (IDH) do Brasil de 2005 a 2014

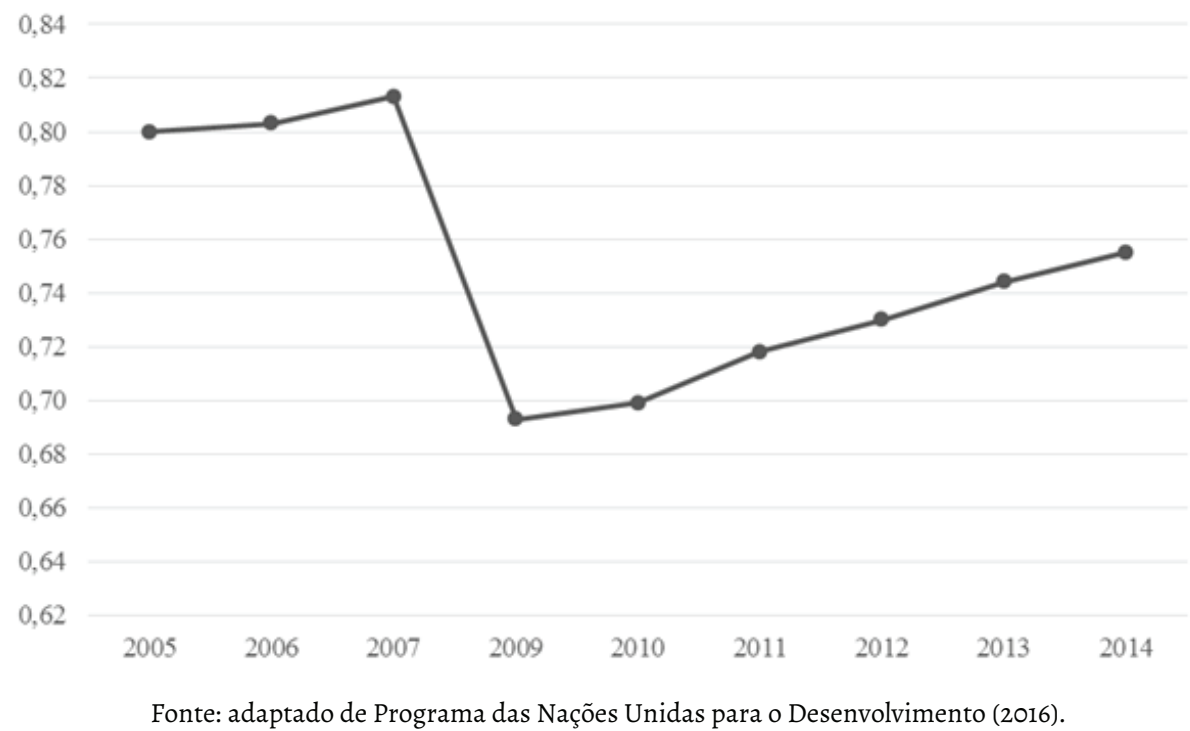

O IDH se eleva de 2005 até 2007 ficando acima de 0,8 índice que representa os países com desenvolvimento humano elevado. (PROGRAMA DAS NAÇÕES UNIDAS PARA O DESENVOLVIMENTO , 2016) No ano de 2009 o IDH brasileiro passa para 0,69 . O que é explicado pela mudança de metodologia, o que o tornou um indicador mais criterioso. As reduções foram constatadas no Brasil, assim como em outros países. No entanto, a partir de 2009, mesmo com a nova metodologia, o IDH brasileiro continua crescendo.

Embora não se possa afirmar com certeza, pode-se supor que esse crescimento contínuo do IDH tem influência da expansão do PBF, já que este aumentou as condições de saúde e educação, bem como a renda per capita da população.

$\mathrm{O}$ PBF tem impacto positivo tanto no IDH quanto no Produto Interno Bruto (PIB) do país, visto que o mesmo é uma política de Estado que tem conseguido melhorar as condições de vida da população brasileira, principalmente na Região Nordeste do país. (PADRONES et al., 2015) Diretamente o PBF afeta o IDH através da renda, já indiretamente e ao longo do tempo, o impacto deve ser percebido nas demais variáveis.

\section{CONSIDERAÇÕES FINAIS}

O PBF é o principal programa social brasileiro de redução da pobreza e das desigualdades a partir da transferência de recursos monetários para as famílias em estado de extrema pobreza. (ESTRELLA; RIBEIRO, 2008) A gestão e o acompanhamento das condicionalidades do PBF envolvem um complexo mecanismo institucional que demanda a articulação dos três entes federativos 
(união, estados e municípios) e diferentes setores (saúde, educação e assistência social), mobilizando diversos atores sociais. (SENNA; BRANDÃO; DALT, 2016)

Foi possível verificar que as condicionalidades do PBF têm sido cumpridas, tanto na área da saúde quando na área da educação. Na área da saúde houveram alguns entraves, sobretudo nos anos iniciais, para o atendimento às famílias beneficiárias, tais como falta de profissionais e infraestrutura para atender crianças e gestantes.

Já com relação à educação, os resultados da condicionalidade extrapolam a frequência escolar. Acredita-se na efetividade da condicionalidade no momento que ações de educação se concretizam com políticas de desenvolvimento e são mensuradas a médio e longo prazo.

Por outro lado, apesar do programa ser efetivo com relação as condicionalidade ligadas a saúde e a educação, é necessário uma reavaliação dos mecanismos de controle. Deve-se ir além da frequência escolar, analisando os conteúdos e conhecimentos adquiridos. Também na saúde, é preciso avançar no número de atendidos e melhorar a infraestrutura e o capital humano dos postos de saúde onde estão sendo atendidos os beneficiários do $\mathrm{PBF}$.

Por fim, apesar das críticas e das necessárias e urgentes mudanças no PBF, destaca-se a relevância que o programa possui para o desenvolvimento, sobretudo para a melhoria da qualidade e da esperança de vida da população beneficiária. O Programa Bolsa Família atua na redução da pobreza e miséria, garantindo renda e circulação de mercadorias nas regiões mais carentes do país.

\section{REFERÊNCIAS}

ALBUQUERQUE NETO, L. C. de et al. Programa Nacional de Alimentação Escolar como Incentivo Educacional na cidade de Aracati (CE). In: CONGRESSO BRASILEIRO DE ECONOMIA, 21., 2015, Curitiba. Anais [...] Curitiba: CORECONPR, 2015.

BATISTA, E. M. da S. Programa Bolsa Família: condicionalidades, focalização e valor do benefício. 2007. 67 f. Monografia (Especialização em Orçamento Público) - Câmara dos Deputados, Centro de Formação Treinamento e Aperfeiçoamento, Brasília, DF, 2007.

BRASIL. Ministério do Desenvolvimento Social e Agrário. Condicionalidades. 2015. Disponível em: http://mds.gov.br/assuntos/bolsa-familia/gestao-do-programa/ condicionalidades. Acesso em: 18 ago. 2016.

BRASIL. Ministério do Desenvolvimento Social e Agrário. Condicionalidades. $2016 a$. Disponível em: http://mds.gov.br/assuntos/bolsa-familia/gestao-doprograma/ condicionalidades. Acesso em: 18 ago. 2016.

BRASIL. Ministério do Desenvolvimento Social e Agrário. Sistema Data Social. 2016b. Disponível em: https://aplicacoes.mds.gov.br/sagi/portal/pesquisa.php?valor=data\%20 social. Acesso em: 13 jul. 2016. 
CAMPELLO, T.; NERI, M. C.(org.). Programa Bolsa Família: uma década de inclusão e cidadania. Brasília, DF: IPEA, 2013.

CARVALHO, A. T. de; ALMEIDA, E. R. de; JAIME, P. C. Condicionalidades em saúde do programa Bolsa Família - Brasil: uma análise a partir de profissionais da saúde. Saúde e Sociedade, São Paulo, v. 23, n. 4, p.1370-1382, 2014.

CASTRO, L. B. de. Privatização, abertura e desindexação: a primeira metade dos anos 90 (1990-1994). In: GIAMBIAGI, F. et al. (org.) Economia brasileira contemporânea: 19452010. Rio de Janeiro: Elsevier, 2005. p.131-164.

CRAVEIRO, C. B. A.; XIMENES, D. de A. Dez anos do Programa Bolsa Família: desafios e perspectivas para a universalização da educação básica no Brasil. In: CAMPELLO, T.; NERI, M. C.(org.). Programa Bolsa Família: uma década de inclusão e cidadania. Brasília, DF: IPEA, 2013. p. 23-24.

CRESPO, A. P. A., GUROVITZ, E. A pobreza como um fenômeno multidimensional. RAE-eletrônica, São Paulo, v. 1, n. 1, p.2-12, jul./dez. 2002. Disponível em: http://www.scielo.br/pdf/raeel/vin2/vin2a03.pdf. Acesso em: 30 abr. 2016

CUNHA, L. A. da. Renda mínima, consumo e cidadania: o caso do programa bolsa família em Areia Branca-RN. Revistainter-legere, Natal, n. 11, p. 90-110, 2012.

DATASUS. Portal do Bolsa Família. 2016. Disponível em: http://bolsafamilia.datasus.gov. br/w3c/bfa.asp. Acesso em: 05 jul. 2016.

ESTRELLA, J., RIBEIRO, L. M. Qualidade da gestão das condicionalidades do Programa Bolsa Família: uma discussão sobre o índice de gestão descentralizada. Revista de Administração Pública, Rio de Janeiro, v. 42, n. 3, p. 625-641, maio/jun. 2008.

FAHEL, M. C. X.; FRANÇA, B. C.; MORAES, T. O efeito da condicionalidade educação do Bolsa Família em Minas Gerais: uma avaliação por meio da PAD/MG. Revista Brasileira de Monitoramento e Avaliação, Brasília, DF, n. 2, p. 4-25, jul./dez. 2011.

FERRER, F. P. Bolsa Família e desigualdade de gênero: uma análise sob a perspectiva da abordagem das capacitações. 2015. 69 f. Monografia (Graduação em Ciências Econômicas) - Universidade Federal do Rio Grande do Sul, Porto Alegre, 2015.

FERRO, A. R.; KASSOUF, A. L. Avaliação do impacto dos programas bolsa-escola sobre o trabalho infantil no Brasil. Revista Pesquisa e Planejamento Econômico, Rio de Janeiro, v. 35 , n. 3 p. 417-444, dez. 2005.

GIAMBIAGI, F. Estabilização, reformas e desequilíbrios macroeconômicos: os anos FHC (1995-2002). In: GIAMBIAGI, F.; VILLELA, A.; CASTRO, L. B.; HERMANN, J. (org.) Economia Brasileira Contemporânea: 1945-2004. Rio de Janeiro: Elsevier, 2005. p. 166-195.

INSTITUTO DE PESQUISA ECONÔMICA APLICADA. Objetivos de desenvolvimento do Milênio: relatório nacional de acompanhamento. Brasília, DF, 2010. Disponível em: http://www.redeblh.fiocruz.br/media/relnacodm.pdf>. Acesso em: 2 maio 2016. 
JESUS, F. F. de; SILVA, M. da C.; BOAVENTURA, V. C. Politicas públicas e programas de transferência de renda: o impacto do benefício de prestação continuada (BPC) e do Programa Bolsa Família (PBF) na vida dos idosos residentes nas cidades de Cachoeira e São Félix-BA. Cruz das Almas: Editora UFRB, 2012.

LEÃO, R. S. Caracterização da pobreza na região centro-sul do Rio Grande do Sul, no período de 1991 a 2000, sob o enfoque das capacitações. 2004. 186 f. Dissertação (Mestrado em Ciências Econômicas) - Faculdade de Ciências Econômicas, Universidade Federal do Rio Grande do Sul, Porto Alegre, 2004.

MARANGONI, G. Anos 1980, década perdida ou ganha? Desafios do Desenvolvimento, Brasília, DF, ano 9, edição 72, p. 56-65, 2012.

MONTEIRO, D. A. A., FERREIRA, M. A. M., TEIXEIRA, K. M. A. Determinantes da gestão do Programa Bolsa Família: análise do índice de gestão descentralizada em Minas Gerais. Saúde Sociedade, São Paulo, v. 18, n. 2, p. 214-226, 2009.

NERI, M. C.; MELO, L. C. C.; MONTE, S. dos R. S. Superação da pobreza e a nova classe média do campo. Brasília, DF: FGV, 2012.

PADRONES, K. et al., Análise da distribuição do Bolsa Família: um programa de governo ou de estado? Revista Mineira de Contabilidade, Belo Horizonte, v. 16, n. 3, p.61-71, 2015.

PAES-SOUZA, R., RAMALHO, W. M., FORTALEZA, B. M. Pobreza e desnutrição: uma análise do Programa Fome Zero sob uma perspectiva epidemiológica. Saúde e Sociedade, São Paulo, v. 12, n. 1, p.21-30, jan./jun. 2003.

PIRES, A. Afinal, para que servem as condicionalidades em educação do Programa Bolsa Família? Ensaio: Avaliação e Políticas Públicas em Educação, Rio de Janeiro, v. 21, n. 80 , p. 513-532, jul./set. 2013.

PROGRAMA DAS NAÇÕES UNIDAS PARA O DESENVOLVIMENTO. Relatórios de desenvolvimento humano. Brasília, DF, 2016. Disponível em: http://www.br.undp. org/content/dam/brazil/docs/RelatoriosDesenvolvimento/undp-br-2016-humandevelopment-report-2017.pdf. Acesso em: 20 jul. 2016.

ROCHA, S. M. R. da. Pobreza no Brasil: afinal, de que se trata? Rio de Janeiro: Editora FGV, 2003.

ROCHA, S. Transferências de renda no Brasil: o fim da pobreza? Rio de Janeiro: Elsevier, 2013.

SAMUELSON, P. A.; NORDHAUS, W. D. Economia. 3. ed. Rio de Janeiro: McGraw-Hill, 2004.

SCHWARTZMAN, S. Education-oriented social programs in Brazil: the impact of Bolsa Escola. [S.l.: s.n.], 2005.

SEN, A. Desenvolvimento como liberdade. São Paulo: Companhia de Bolso, 2000. 
SENNA, M. de C. M.; BRANDÃO, A. A.; DALT, S. da. Programa Bolsa Família e o acompanhamento das condicionalidades na área de saúde. Serviço Social \& Sociedade, São Paulo, n. 125, p. 148-166, jan./abr. 2016.

SILVA, C. A. da; DALT, S. da. O Programa Bolsa Família: impactos provocados pelo cumprimento de condicionalidades de saúde e provável articulação com o Programa Saúde da Família. In: CONGRESSO DA SOCIEDADE BRASILEIRA DE SOCIOLOGIA, 14., 2009, Rio de Janeiro. Anais [...] Rio de Janeiro: Sociedade Brasileira de Sociologia, 2009. Paginação irregular.

SILVA, M. O. da S. e. Os programas de transferência de renda e a pobreza no Brasil: superação ou regulação? Revista de Políticas Públicas, São Luís, v. 9, n. 1, p. 251-278, jul./dez. 2005.

SOARES, S.; SÁTYRO, N. O Programa Bolsa Família: desenho institucional, impactos e possibilidades futuras. Brasília, DF: IPEA, 2009. (Texto para Discussão, 1424).

SOUZA, A. P. Fighting long-run poverty in Brazil: are conditional cash transfer programs making a difference?. [S.l.: s.n.], 2006.

SOUZA, N. R. Economia brasileira contemporânea: de Getúlio a Lula. 2. ed. São Paulo: Atlas, 2008.

SOUZA, P. H. G. F. de; OSORIO, R. G. SOARES, S. S. D. Uma metodologia para simular o Programa Bolsa Família. Brasília, DF: IPEA, 2011. (Texto para Discussão, 1654).

SOUZA, R. P.; RAMALHO, W. M.; FORTALEZA, B.M. Pobreza e desnutrição: uma análise do Programa Fome Zero sob uma perspectiva epidemiológica. Saúde e Sociedade, São Paulo, v. 12, n. 1, p. 21-30, 2003.

TAVARES, P. A. et al. Uma avaliação do Programa Bolsa Família: focalização e impacto na distribuição de renda e pobreza. Pesquisa e Planejamento Econômico, Rio de Janeiro, v. 39, n. 1, p. 25-58, abr. 2009.

VALENTE, A. L. O Programa Nacional de Bolsa Escola e as ações afirmativas no campo educacional. Revista Brasileira de Educação, Rio de Janeiro, n. 24, p. 165-182, set./dez. 2003. 